\title{
SISTEM PEMANTAUAN DAN KONTROL OTOMATIS KUALITAS AIR BERBASIS IOT MENGGUNAKAN PLATFORM NODE-RED UNTUK BUDIDAYA UDANG
}

\author{
${ }^{1}$ Ahmad Rifa'i, ${ }^{2}$ M. Udin Harun Al Rasyid, ${ }^{3}$ Agus Indra Gunawan \\ 1,2,3 Politeknik Elektronika Negeri Surabaya (PENS) \\ Email: ${ }^{1}$ ahmrifai.ar@gmail.com, ${ }^{2}$ udinharun@pens.ac.id, ${ }^{3}$ agus_ig@pens.ac.id
}

\begin{abstract}
Abstrak
Kualitas air dalam budidaya udang adalah faktor penting yang perlu diperhatikan. Sehingga kualitas air yang baik menjadi tolak ukur tingkat keberhasilan budidaya udang. Permasalahan utamanya adalah buruknya kualitas air selama masa pemeliharaan. Untuk mengatasi masalah tersebut, penelitian ini bertujuan menggunakan perangkat Internet of things (IoT) yang dapat memantau kondisi kualitas air dan melakukan tindakan pencegahan berupa perberitahuan dini dan kontrol otomatis pada tiap-tiap aktuator di kolam budidaya. Beberapa sensor yang digunakan seperti Dissolved Oxygen (DO), Hydrogen Potential $(\mathrm{pH})$, Turbidity, Suhu air dan Ketinggian air (Sensor ultrasonic). Selanjutnya data kualitas air akan dikirimkan ke server (Node-Red Platform) menggunakan komunikasi protokol MQTT (Message Queue Telemetry Transport). Pengolahan data yang dilakukan di Server menggunakan metode IFTTT (If This Then That) dan menghasilkan keputusan berupa perintah (command set) untuk mengontrol aktuator pada Node kontrol aktuator. Dari hasil pengujian performa, delay yang terjadi pada pengiriman data dari publisher ke subscriber diperoleh rata-rata $260 \mathrm{~ms}$ dengan menggunakan publik Broker HIVEMQ. Sedangkan pada pengujian kontrol otomatis, grafik respon menunjukan adanya aksi yang dilakukan oleh alat kontrol aktuator setelah mendapatkan command set yang dihasilkan metode IFTTT pada platform Node-Red.
\end{abstract}

Kata Kunci: Budidaya udang, IoT, MQTT, IFTTT, Node-Red

\begin{abstract}
Water quality in shrimp farming is an important factor that needs attention. Therefore good water quality becomes a measure of the success rate of shrimp cultivation. The main problem is the poor quality of water during the maintenance period. To overcome this problem, this paper proposes to use an Internet of things (IoT) device that can monitor water quality conditions and take preventive measures in the form of early notification and automatic control of each actuator in the cultivation pond. Some of the sensors used are Dissolved Oxygen (DO), Hydrogen Potential ( $p H)$, Turbidity, Water temperature and water level (ultrasonic sensor). Furthermore, water quality data will be sent to the server (Node-Red Platform) using the MQTT (Message Queue Telemetry Transport) protocol communication. Data processing carried out on the server uses the IFTTT (If This Then That) method and produces a decision in the form of a command (command set) to control the actuator on the actuator control node. From the performance test results, the delay occurs in sending data from the publisher to the subscriber is an average of $260 \mathrm{~ms}$ using the public HIVEMQ Broker. Whereas in automatic control testing, the response graph shows the action taken by the actuator control device after getting the command set generated by the IFTTT method on the Node-Red platform.
\end{abstract}

Keywords: Shrimp farming, IoT, MQTT, IFTTT, Node-Red 


\section{PENDAhULUAN}

Indonesia merupakan Negara maritim. Berdasarkan data yang diperoleh dari kementrian kelautan dan perikanan bahwa $25,74 \%$ wilayah Indonesia adalah daratan, 41,61\% adalah lautan dan $32,65 \%$ adalah wilayah Zona Ekonomi Eksklusif (ZEE) (Rahmantya et al., 2018). Berdasarkan data tersebut dapat disimpulkan bahwa Negara Indonesia memiliki luas perairan yang lebih besar dibandingkan luas daratannya, sehingga dari fakta tersebut Indonesia memiliki potensi yang sangat besar dari sisi produktifitas perikanan (Rahmantya et al., 2018).

Produktifitas perikanan di Indonesia terbagi menjadi tiga jenis, diantaranya adalah perikanan tangkap laut, perikanan tangkap PUD (Perairan Umum Daratan) dan perikanan budidaya (Akuakultur). Namun dari ketiga jenis produktifitas perikanan tersebut yang konsisten terus mengalami peningkatan produktifitas setiap tahunnya adalah dari jenis produktifitas akuakultur (Ghufron et al., 2018).Tercatat pada data statistik dari tahun 2012 hingga tahun 2017 bahwa Akuakultur terus mengalami rata-rata kenaikan sebesar $11,5 \%$ pada tiap tahunnya (Rahmantya et al., 2018).

Meskipun Akuakultur memiliki potensi yang besar dan konsisten mengalami kenaikan, pada kenyataannya memiliki banyak resiko dan tidak sedikit pembudidaya mengalami gagal panen (Saragih et al., 2015). Hal tersebut diakibatkan karena kurangnya pemahaman yang dimiliki oleh pembudidaya dan juga cara budidaya yang digunakan masih menggunakan cara-cara yang konvensional (Madhavireddy \& Koteswarrao, 2018).

Komoditas udang merupakan salah satu komoditas perikanan budidaya di Indonesia yang memiliki tingkat resiko yang paling tinggi dibandingkan komoditas lainnya (Utojo \& Tangko, 2008). Komoditas udang memiliki sifat yang sensitif terhadap perubahan kualitas air, sehingga memerlukan kondisi kualitas air yang stabil untuk dapat bertahan hidup. Kualitas air dalam budidaya udang harus terus dijaga agar selalu dalam kondisi yang baik. Parameter kualitas air yang perlu diperhatikan dalam budidaya udang diantaranya adalah kandungan Dissolved Oxygen (DO), Hydrogen Potential $(\mathrm{pH})$, Turbidity, Suhu dan Ketinggian air (Atmomarsono et al., 2014). Parameter-parameter kualitas air tersebut harus terus dijaga pada nilai standarnya masing-masing yang sudah ditentukan, agar udang terus mengalami pertumbuhan dan terhindar dari penyakit, sehingga udang akan lebih lama bertahan hidup hingga waktu masa panen tiba (Supono, 2017).

Solusi dari permasalahan tersebut adalah penerapan teknologi IoT untuk mengambil kondisi kualitas air serta penggunaan metode pengolahan data untuk memberikan kontrol secara otomatis pada kualitas air kolam budidaya. Beberapa penelitian sebelumnya yang telah mengimplementasikan teknologi IoT diantaranya adalah pengembangan sistem manajemen kualitas air untuk budidaya ikan lele, dimana data kualitas air yang telah diambil melalui perangkat IoT selanjutnya akan diolah menggunakan Fuzzy logic untuk melakukan kontrol suhu dan amonia dalam air (Rozie et al., 2020). Pengiriman data yang realtime merupakan bagian utama dalam pengembangan teknologi IoT. Beberapa protokol IoT yaitu MQTT, CoAp, AMQP, dan Websocket telah banyak diimplementasikan dalam pengembangan sistem berbasis IoT (Balakrishnan, S; Rani, S. Sheeba; Ramya, 2019; Dzulqornain et al., 2018; Rozie et al., 2020).

Pemanfaatan terknologi IoT pada bidang akuakultur akan dapat membantu produktifitas pembudidaya dalam hal pemantauan kondisi kualitas air dan rekomendasi tindakan (Balakrishnan, S; Rani, S. Sheeba; Ramya, 2019). Penelitian ini mengajukan suatu sistem yang dapat digunakan untuk memantau kondisi kualitas air serta dapat mengontrol aktuator pengkondisian air kolam budidaya dan memberikan early warning notification dengan metode IFTTT (If This Then That) secara realtime menggunakan protokol MQTT. Data kualitas air akan diambil oleh alat akuisisi data. Selanjutnya data kualitas air akan dikirimkan dan diolah disisi Server (Node-Red) sehingga menghasilkan keputusan berupa command set yang digunakan untuk menggontrol aktuator dan memberikan early warning notifiation.

\section{METODE}

\section{Desain Sistem}

Penelitian ini mengajukan suatu sistem yang dapat digunakan oleh para pembudidaya untuk memantau kondisi kualitas air dan memberikan rekomendasi aksi menggunakan platform Node-Red dan metode IFTTT. Platform Node-Red digunakan untuk melakukan pemantauaan dengan mengimplementasikan beberapa komponen antarmuka yang telah disediakan (Mulyono et al., 2018; Wiguna \& Subari, 2017). Sedangkan metode IFTTT digunakan untuk meberikan keputusan dengan input parameter kualitas air yang dikirimkan oleh alat akuisisi data (Dzulqornain et al., 2018). Pada desain sistem penelitian ini yang dapat dilihat 
pada Gambar 1 terdiri atas empat blok komponen utama yaitu Alat akuisisi data, MQTT Broker, Platform Node-Red dan Alat kontrol aktuator.

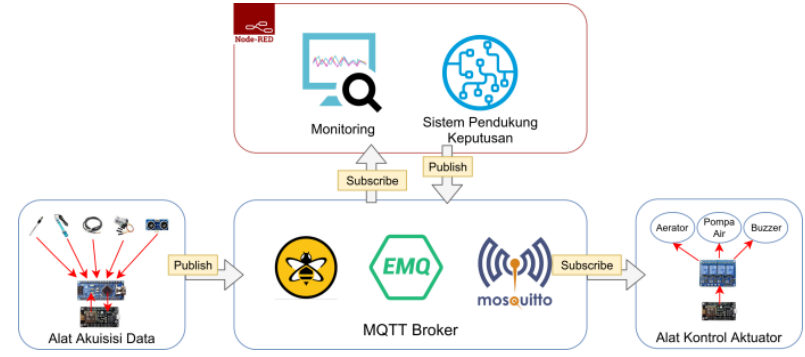

Gambar 1. Desain Sistem

\section{Alat Akuisisi Data}

Alat akuisisi data terdiri dari sensor-sensor, mikrokontroller Arduino Nano, NodeMCU dan adaptor 5V. Arduino Nano berfungsi sebagai pengolah sinyal dari sensor-sensor. Sedangkan NodeMCU berfungsi sebagai gateway untuk berkomunikasi dengan server sebagaimana yang ditunjukan pada Gambar 2. Sensor yang digunakan dalam penelitian ini yaitu sebagai berikut:

- Sensor Dissolved Oxygen (DO) digunakan untuk mengambil data kandungan oksigen terlarut dalam air (Balakrishnan, S; Rani, S. Sheeba; Ramya, 2019; Lin \& Tseng, 2019). Rentang data DO untuk budidaya udang yang baik adalah lebih dari $4 \mathrm{mg} / \mathrm{l}$ (ppm) (>4 ppm) (Supono, 2017).

- Sensor Hydrogen Potential (pH) digunakan untuk mengetahui tingkat keasaman air. Kandungan $\mathrm{pH}$ yang baik untuk budidaya udang adalah berada antara 7,5 sampai 8,5 (Supono, 2017).

- Sensor Temperature digunakan untuk mengambil data suhu air. Sensor yang digunakan adalah jenis DS18B20 dengan pelindung luar terbuat dari besi stainlees. Suhu yang bagus untuk pertumbuhan udang berkisar antara $26-33{ }^{\circ} \mathrm{C}$ (Supono, 2017).

- Sensor Turbidity digunakan untuk mengambil data tingkat kekeruhan air. Tingkat kekeruhan air yang optimal untuk budidaya udang adalah 30-50 cm (Supono, 2017) atau setara dengan 11-24 NTU (Nephelometric Turbidity Unit). Semakin dalam tingkat kekeruhan menandakan bahwa air tersebut jernih, namun sebaliknya apabila nilai NTU semakin besar menandakan air tersebut keruh (Myre \& Shaw, 2006).

- Sensor Water Level menggunakan jenis sensor ultrasonic tipe HCSR-04. Sensor tersebu digunakan untuk mengetahui tingkat ketinggian air kolam.

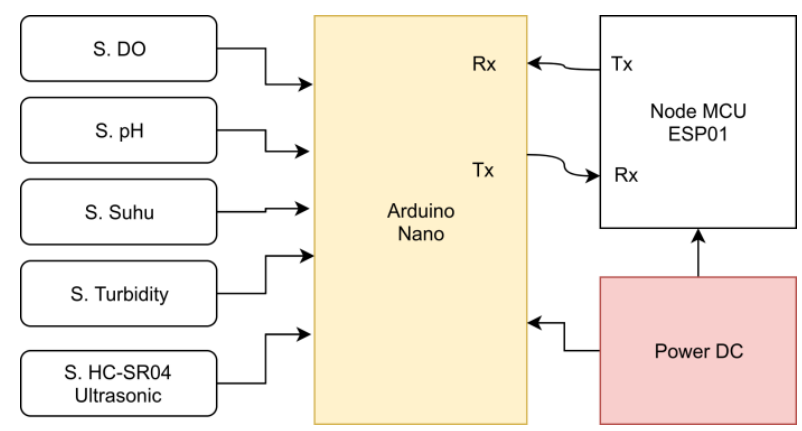

Gambar 2. Diagram blok alat akuisisi data

Data kualitas air yang telah diperolah dari tiaptiap sensor, selanjutnya akan dikumpulkan oleh Arduino nano dan dikirimkan ke NodeMCU melalui komunikasi serial.

\begin{tabular}{|c|c|c|c|c|c|c|c|c|c|c|c|}
\hline $\begin{array}{l}\text { Data } 1 \\
\text { Waktu }\end{array}$ & \# & $\begin{array}{c}\text { Data } 2 \\
\text { DO }\end{array}$ & \# & $\begin{array}{c}\text { Data } 3 \\
\mathrm{pH}\end{array}$ & \# & $\begin{array}{c}\text { Data } 4 \\
\text { Suhu }\end{array}$ & $\#$ & \begin{tabular}{|c|} 
Data 5 \\
Turbidity
\end{tabular} & \# & $\begin{array}{l}\text { Data } 6 \\
\text { Water } \\
\text { Level }\end{array}$ & Data Karakter \\
\hline 23 & 1 & 4 & 1 & 4 & 1 & 2 & 1 & 3 & 1 & 3 & Satuan Byte \\
\hline
\end{tabular}

Gambar 3. Paket data kualitas air

Metode yang digunakan untuk mengirimkan data ke server yaitu dengan metode publish dan subscribe menggunakan protokol MQTT. NodeMCU akan melakukan publish data dengan topik: sensor/\{id_alat\}/data, serta payload-nya berupa format data yang ditunjukan pada Gambar 3. Ilustrasi pengiriman daa ke MQTT Broker yang dilakukan oleh tiap-tiap alat akusisi data dapat dilihat pada Gambar 4.

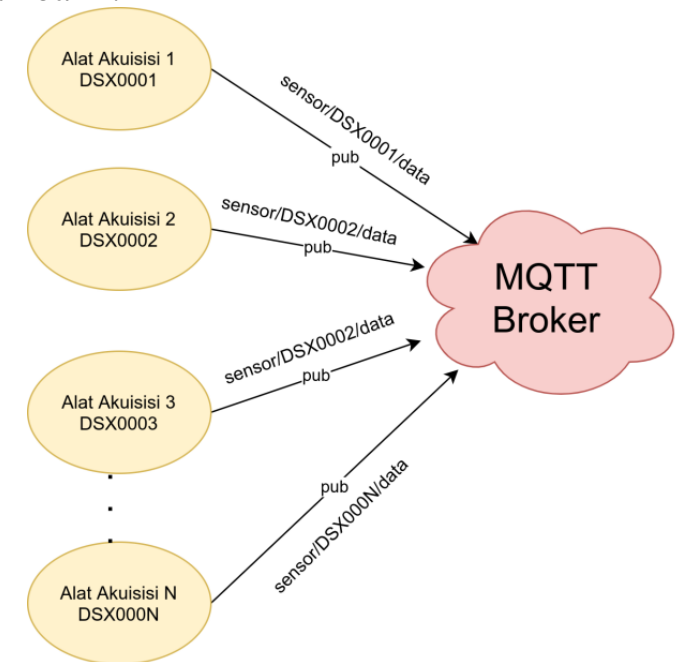

Gambar 4. Publish data oleh tiap-tiap alat akuisisi

\section{MQTT Broker}

MQTT Broker berfungsi sebagai media yang menghubungkan antara node publisher dan node subscriber (Abadi et al., 2020) dimana pada penelitian ini yang memiliki peran sebagai publisher adalah alat akuisisi data. Sedangkan yang berfungsi sebagai subscriber adalah alat kontrol aktuator. Namun yang memiliki peran ganda yaitu sebagai 
publisher sekaligus subscriber adalah Server atau Aplikasi Node-Red.

Pada penelitian ini digunakan beberapa publik MQTT Broker yang telah tersedia dan dapat diakses secara umum. Berikut adalah daftar publik MQTT Broker yang digunakan dapat dilihat pada Tabel I.

Table I Publik MQTT Broker

\begin{tabular}{|l|l|c|c|c|c|}
\hline \multirow{2}{*}{\multicolumn{1}{|c|}{ Nama }} & \multirow{2}{*}{ Host } & \multicolumn{4}{c|}{ Port } \\
\cline { 3 - 6 } EMQX & TCP & TLS & WS & WSS \\
\hline HIVEMQ & broker.emqx.io & 1883 & 8883 & 8083 & 8084 \\
\hline MOSQUITTO & test.mosquitto.org & 1883 & 8883 & 8080 & 8081 \\
\hline
\end{tabular}

\section{Alat Kontrol Aktuator}

Alat kontrol aktuator berfungsi untuk mengontrol aktuator yang ada dikolam budidaya. Aktuator yang ada dikolam budidaya diantaranya adalah pompa air dan aerator. Sedangkan untuk memberikan peringatan di area kolam budidaya disediakan juga buzzer. Alat kontrol aktuator dalam penelitian ini terdiri atas NodeMCU, Relay dan Buzzer.

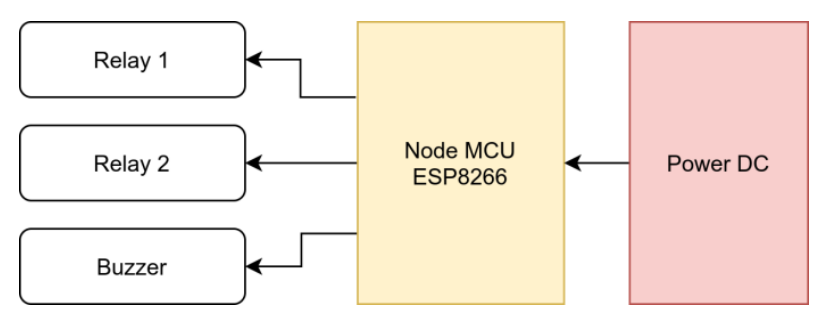

Gambar 5. Diagram blok alat kontrol aktuator

Alat kontrol aktuator akan melakukan subscribe ke MQTT Broker untuk mendapatkan perintah yang telah ditentukan oleh sistem pendukung keputusan. NodeMCU yang telah terkoneksi ke internet melakukan subscribe ke MQTT Broker dengan topik subscribe: actuator/\{id_alat\}, sedangkan data payload-nya memiliki format yang dapat dilihat pada Gambar 6, dimana Data 1 merupakan identitas dari relay yang akan dikontrol. Dalam penelitian ini, identitas relay diberikan nama R1, R2 dan R3. Selanjutnya untuk Data 2 yang berisikan nilai State yaitu ON atau OFF.

\begin{tabular}{|c|c|c|c|}
\hline $\begin{array}{l}\text { Data } 1 \\
\text { Relay }\end{array}$ & $\#$ & $\begin{array}{c}\text { Data } 2 \\
\text { State }\end{array}$ & Data Karakter \\
\hline 2 & 1 & 3 & Satuan Byte \\
\hline
\end{tabular}

Gambar 6. Format data kontrol aktuator

Diagram blok proses subscribe yang dilakukan oleh alat kontrol aktuator ke MQTT Broker dapat dilihat pada Gambar 7.

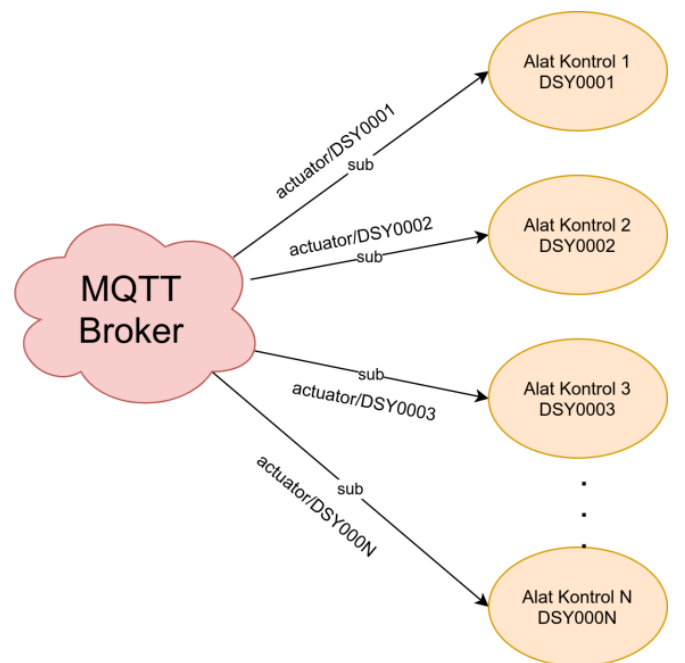

Gambar 7. Subscribe topik oleh tiap-tiap alat kontrol aktuator

\section{Flow Sistem Pada Platform Node-Red}

Node-Red merupakan sebuah platform yang menyediakan beberapa tools yang dapat digunakan untuk membuat suatu sistem berbasis Internet of Things (IoT) (Wiguna \& Subari, 2017). Sistem yang dibangun pada platform Node-Red menggunakan beberapa komponenen node yang membentuk flow. Flow untuk melakukan monitoring pada Gambar 8 terdiri atas node subscriber, node function, node gauge dan node chart.

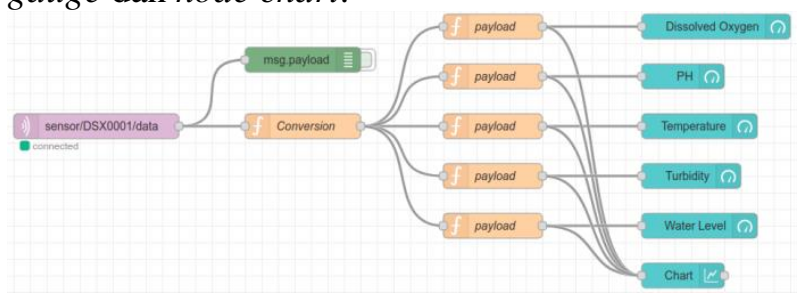

Gambar 8. Flow Node-Red untuk sistem monitoring

Sedangkan untuk melakukan kontrol aktuator telah dirancang juga flow kontrol otomatis dan kontrol manual. Flow kontrol otomatis pada Gambar 9 terdiri atas node subscriber, node function konversi data, node function IFTTT dan node publisher. Flow kontrol manual pada Gambar 10 terdiri dari node inject dan node publisher.

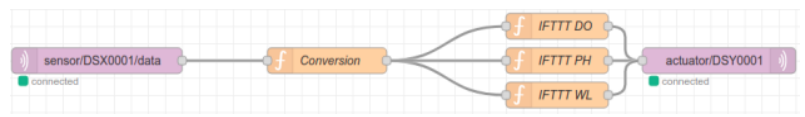

Gambar 9. Flow Node-Red untuk sistem pendukung keputusan 


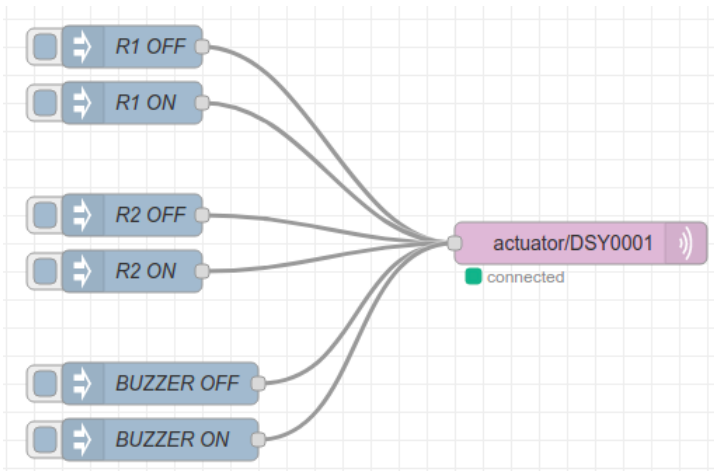

Gambar 10. Flow Node-Red untuk kontrol aktuator secara manual

\section{Sistem Kontrol Otomatis dan Notifikasi}

Sistem kontrol otomatis dan notifikasi berfungsi sebagai early action atau tindakan dan early warning untuk pencegahan dan pemberitahuan apabila terjadi suatu kondisi yang tidak normal. Tindakan yang dihasilkan oleh sistem kontrol otomatis ini berdasarkan rule yang telah ditentukan pada metode IFTTT (Dzulqornain et al., 2018). Rule metode IFTTT yang digunakan pada penelitian ini dapat dilihat pada Tabel II.

Table II IFTTT Rule

\begin{tabular}{|c|c|c|c|c|}
\hline \multirow{3}{*}{ Parameter } & IF This & $\begin{array}{c}\text { THEN } \\
\text { Aerator }\end{array}$ & $\begin{array}{c}\text { THEN } \\
\text { Pump }\end{array}$ & $\begin{array}{c}\text { THEN } \\
\text { Buzzer }\end{array}$ \\
\hline \multirow{3}{*}{$\begin{array}{c}\text { DO } \\
\text { (ppm) }\end{array}$} & $>4$ & OFF & - & - \\
\cline { 2 - 5 } & $>3$ & ON & - & - \\
\cline { 2 - 5 } & $<=3$ & ON & - & ON \\
\hline \multirow{4}{*}{ PH } & $\begin{array}{c}6<= \\
\& \& \\
<=8\end{array}$ & - & - & OFF \\
\cline { 2 - 5 } & $>8$ & - & - & ON \\
\cline { 2 - 5 } & $<6$ & - & - & ON \\
\hline \multirow{3}{*}{$\begin{array}{c}\text { Water } \\
\text { Level } \\
(\mathbf{c m})\end{array}$} & $>500$ & - & OFF & ON \\
\cline { 2 - 5 } & $\begin{array}{c}<00<= \\
\& \& \\
<=500\end{array}$ & - & OFF & - \\
\hline
\end{tabular}

\section{Formula Pengujian Performa}

Skenario pengujian performa dilakukan dengan mengukur delay pengiriman data dengan formula (1).

$$
\text { Delay }=\text { Waktu }_{\text {terima }}-\text { Waktu }_{\text {kirim }}
$$

\section{HASIL DAN PEMBAHASAN}

\section{Pengujian Performa Publik MQTT Broker}

Pengujian performa pada publik MQTT Broker dilakukan dengan melakukan pengiriman dummy data dengan paket data yang konsisten yang telah ditentukan sebelumnya seperti yang dapat dilihat pada Gambar 3. Besaran payload yang dikirimkan adalah 44 byte, dapat dilihat pada Gambar 11 .

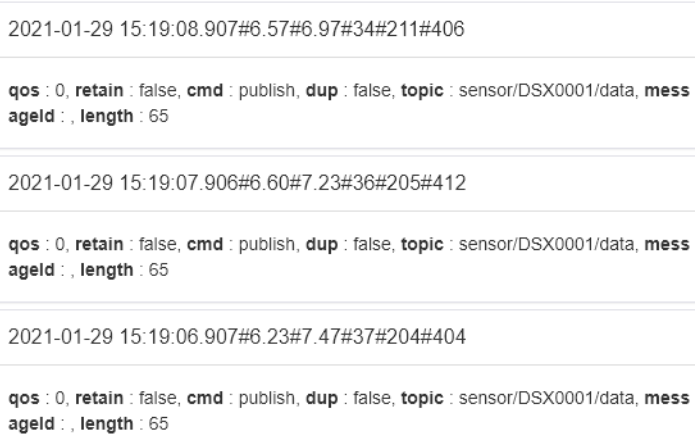

Gambar 11. Paket data yang di-publish oleh publisher

Setelah data berhasil di-publish maka dari sisi subscriber akan menerima data tersebut. Data yang berhasil diterima akan disimpan dalam bentuk file logger seperti yang terlihat pada Gambar 12.

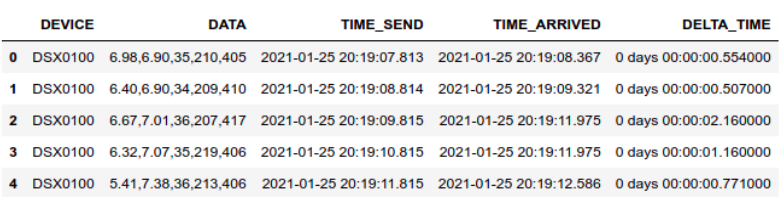

Gambar 12. Data logger uji performa MQTT Broker

Berdasarkan data logger tersebut dapat dihitung lama waktu pengiriman data (delay) dari publisher hingga sampai ke subscriber dengan perhitungan seperti yang ditunjukan pada formula (1).

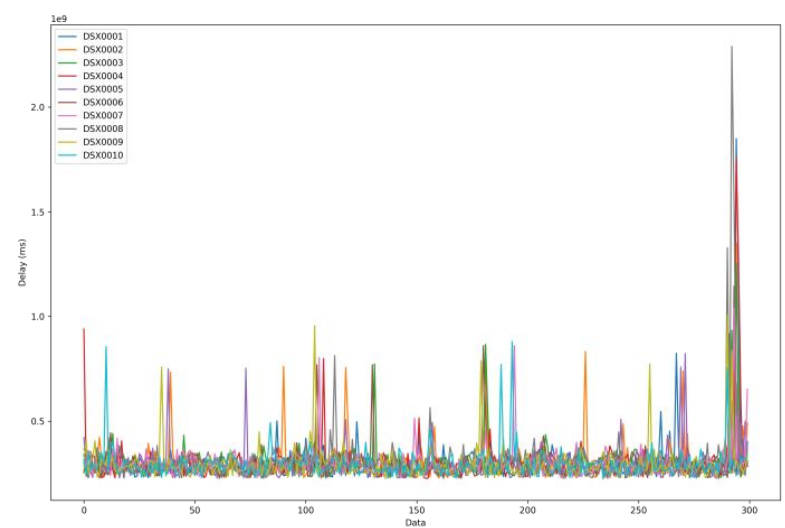

Gambar 13. Grafik delay pengiriman data dari 10 publisher ke subscriber menggunakan Broker EMQX 


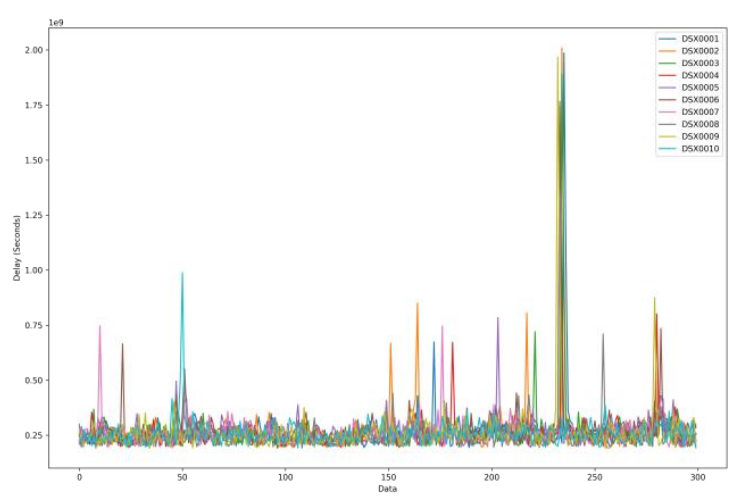

Gambar 14. Grafik delay pengiriman data dari 10 publisher ke subscriber menggunakan Broker HIVEMQ

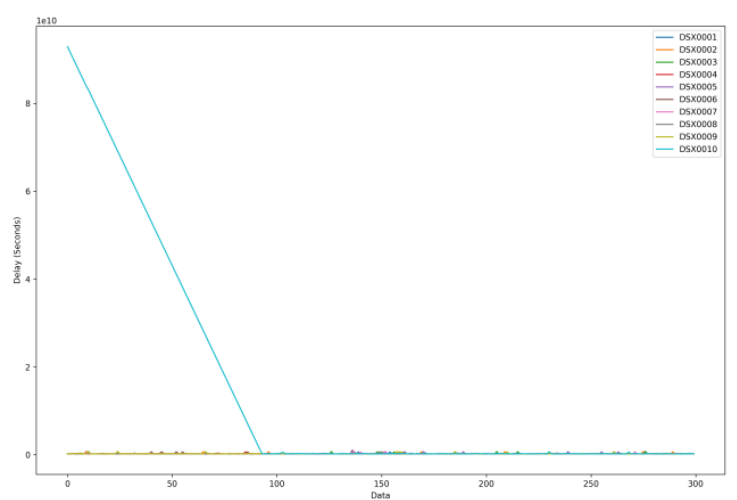

Gambar 15. Grafik delay pengiriman data dari 10 publisher ke subscriber menggunakan Broker Mosquitto

Berdasarkan hasil beberapa percobaan yang telah dilakukan dengan beberapa MQTT Broker yang ditunjukan pada Tabel I didapatkan hasil seperti yang dapat dilihat pada Tabel III.

Table III Tabel Perbandingan Delay Antar Publik MQTT Broker

\begin{tabular}{|c|c|c|c|c|}
\hline \multirow{2}{*}{$\begin{array}{c}\text { Jumlah } \\
\text { Node }\end{array}$} & \multicolumn{3}{|c|}{ Besaran Delay } & \multirow{2}{*}{$\begin{array}{c}\text { Keterangan } \\
\text { Gambar }\end{array}$} \\
\hline & Minimal & Maksimal & Rata-Rata & \\
\hline \multicolumn{5}{|c|}{ Broker EMQX } \\
\hline $\begin{array}{l}10 \\
\text { Publisher }\end{array}$ & $0,2272 \mathrm{~ms}$ & $1,3394 \mathrm{~ms}$ & $0,3014 \mathrm{~ms}$ & \multirow{3}{*}{ Gambar 13} \\
\hline $\begin{array}{l}20 \\
\text { Publisher }\end{array}$ & $0,2276 \mathrm{~ms}$ & $1,0932 \mathrm{~ms}$ & $0,3147 \mathrm{~ms}$ & \\
\hline $\begin{array}{l}30 \\
\text { Publisher }\end{array}$ & $0,2274 \mathrm{~ms}$ & $1,1538 \mathrm{~ms}$ & $0,3008 \mathrm{~ms}$ & \\
\hline \multicolumn{5}{|c|}{ Broker HIVEMQ } \\
\hline $\begin{array}{l}10 \\
\text { Publisher }\end{array}$ & $0,1931 \mathrm{~ms}$ & $1,53 \mathrm{~ms}$ & $0,2635 \mathrm{~ms}$ & \multirow{3}{*}{ Gambar 14} \\
\hline $\begin{array}{l}20 \\
\text { Publisher }\end{array}$ & $0,1925 \mathrm{~ms}$ & $0,6273 \mathrm{~ms}$ & $0,2489 \mathrm{~ms}$ & \\
\hline $\begin{array}{l}30 \\
\text { Publisher }\end{array}$ & $0,1943 \mathrm{~ms}$ & $1,0173 \mathrm{~ms}$ & $0,2672 \mathrm{~ms}$ & \\
\hline \multicolumn{5}{|c|}{ Broker Mosquitto } \\
\hline $\begin{array}{l}10 \\
\text { Publisher }\end{array}$ & $0,1978 \mathrm{~ms}$ & $10,0019 \mathrm{~ms}$ & $1,7079 \mathrm{~ms}$ & Gambar 15 \\
\hline
\end{tabular}

\begin{tabular}{|l|l|l|l|l|}
\hline $\begin{array}{l}\text { 20 } \\
\text { Publisher }\end{array}$ & $173,821 \mathrm{~ms}$ & $278,73 \mathrm{~ms}$ & $226,05 \mathrm{~ms}$ & \\
\cline { 1 - 4 } $\begin{array}{l}\text { 30 Publisher } \\
\text { P }\end{array}$ & $127,03 \mathrm{~ms}$ & $196,55 \mathrm{~ms}$ & $266,12 \mathrm{~ms}$ & \\
\hline
\end{tabular}

\section{Sistem Monitoring}

Sistem monitoring ditampilkan dalam bentuk dua jenis tampilan yaitu Gauge chart dan Line chart secara realtime. Data yang dikirimkan oleh alat akuisisi akan diolah oleh function konversi data dan kemudian disajikan dalam masing-masing paramter kualitas air. Berikut adalah tampilkan monitoring dapat dilihat pada Gambar 16 dan Gambar 17.

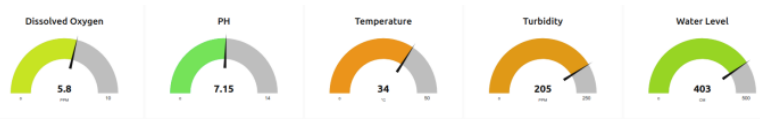

Gambar 16. Gauge chart pembacaan data sensor dari alat akuisisi data secara realtime

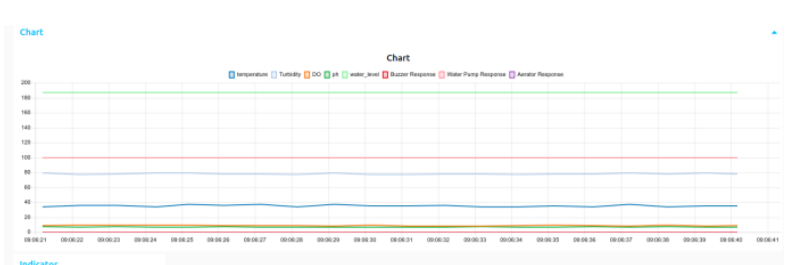

Gambar 17. Line chart pembacaan data sensor dari alat akuisisi data secara realtime

\section{Pengujian Kontrol Otomatis dan Notifikasi}

Skenario pengujian kontrol otomatis dilakukan dengan mellihat respon data yang dihasilkan oleh metode IFTTT. Respon yang dikirimkan dapat dilihat pada logger MQTT Gambar 18 dan divisualisasikan dalam bentuk grafik respon seperti yang dapat dilihat pada Gambar 19, 20 dan 21.

BUZZER\#OFF
qos : 0 , retain : false, cmd : publish, dup : false, topic : a
ctuator/DSY0001, messageld : , length : 28
R2\#ON
qos : 0 , retain : false, cmd : publish, dup : false, topic : a
ctuator/DSY0001, messageld : , length : 23

R1\#ON

Gambar 18. Command set untuk kontrol aktuator 


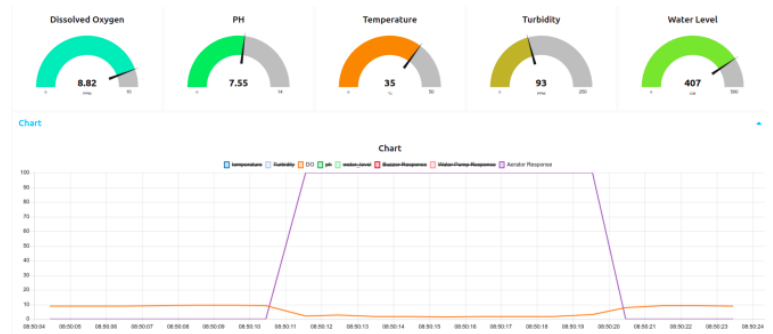

Gambar 19. Respon kontrol aktuator untuk mengontrol

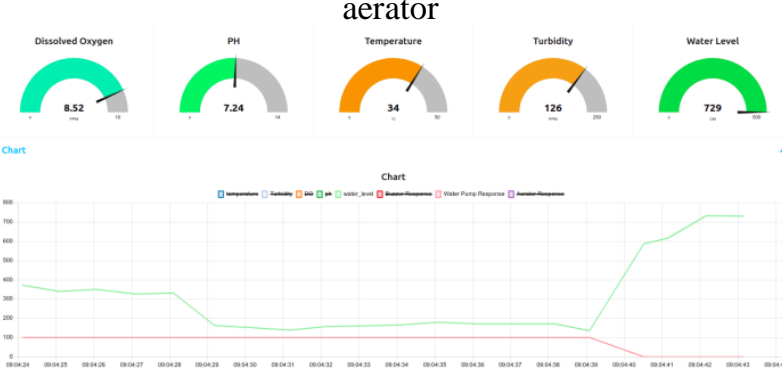

Gambar 20. Respon kontrol aktuator untuk mengontrol water pump

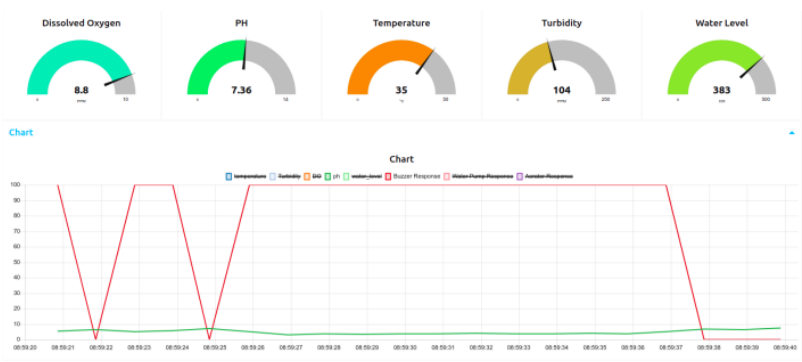

Gambar 21. Respon kontrol aktuator untuk mengontrol buzzer

Pada skenario percobaan kontrol aktuator secara otomatis, Gambar 19 menunjukan respon kontrol aerator aktif (menunjukan nilai 100) terjadi setelah terdeteksi kandungan nilai DO air berada dibawah 3 ppm. Kemudian setelah itu aerator tidak aktif (menujukan nilai 0) setelah kondisi DO air berada pada nilai 8,85 ppm. Selanjutnya pada Gambar 26 merupakan respon dari kontrol water pump. Berdasarkan grafik respon tersebut dapat dilihat bahwa water pump akan selalu aktif jika ketinggian air masih berada dibawah $400 \mathrm{~cm}$. Kemudian setelah ketinggian air berada diatas $400 \mathrm{~cm}$ maka water pump akan dimatikan. Selain melakukan kontrol otomatis pada aktuator-aktuator yang ada dikolam budidaya, diperlukan juga suatu alat alarm sebagai media pemberitahuan atau notifikasi apabila terjadi kondisi-kondisi yang tidak dapat langsung memberikan aksi pada aktuator-aktuator yang ada di kolam budidaya. Gambar 21 merupakan grafik respon dari buzzer sebagai media alarm. Pada grafik tersebut, alarm aktif setelah terdeteksi kandungan $\mathrm{pH}$ air berada dibawah 6 dan berada diatas angka 8 . Apabila terdeteksi kandungan $\mathrm{pH}$ berada pada angka 6 dan 8 maka buzzer akan mati dan menunjukan bahwa kandungan $\mathrm{pH}$ berada pada angka yang optimal. Berikut adalah respon yang pada alat aktuator dapat dilihat pada Gambar 22.

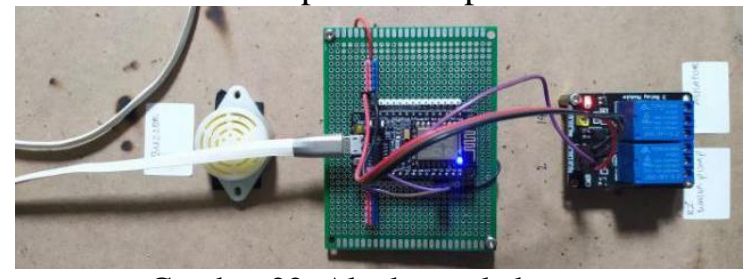

Gambar 22. Alat kontrol aktuator

\section{PENUTUP}

\section{Kesimpulan}

Dalam makalah ini, Data kualitas air yang telah dikumpulkan oleh sensor-sensor parameter kualitas air akan dikirimkan ke Server (Node-Red) menggunakan protocol MQTT dan selanjutnya dilakukan pengolah data menggunakan metode IFTTT untuk menghasilkan keputusan guna mengontrol aktuator dan memberikan early warning notification melalui buzzer. Berdasarkan hasil pengujian, sistem ini telah dapat memantau kualitas air secara realtime dengan rata-rata delay pengiriman paling kecil yaitu $260 \mathrm{~ms}$ diperoleh dengan menggunakan publik MQTT Broker HIVEMQ. Sedangkan rata-rata delay pengiriman paling besar yaitu $141.44 \mathrm{~ms}$ diperoleh dengan menggunakan publik MQTT Broker Test Mosquitto Broker.

\section{DAFTAR PUSTAKA}

Abadi, S. C., Prafanto, A., Eriyadi, M., Suryadi, A., \& Ramadi, G. D. (2020). Penerapan Protokol Publish / Subscribe Messaging System Pada Sistem Wireless Building Network Berbasis Nrf24L01. JTT (Jurnal Teknologi Terapan), 6(2), 172.

Atmomarsono, M., Supito, Mangampa, M., Pitoyo, H., Lideman, S, H. T., Akhdiat, I., Wibowo, H., Ishak, M., Basori, A., Wahyono, N. T., Latief, S. S., \& Akmal. (2014). Budidaya Udang Vannamei (Badrudin (ed.)). WWFIndonesia.

Balakrishnan, S; Rani, S. Sheeba; Ramya, K. C. (2019). Design and Development of IoT Based Smart Aquaculture System in a Cloud Environment. International Journal of Oceans and Oceanography, January.

Dzulqornain, M. I., Harun Al Rasyid, M. U., \& Sukaridhoto, S. (2018). Design and Development of Smart Aquaculture System Based on IFTTT Model and Cloud Integration. MATEC Web of Conferences, 164(May).

Ghufron, M., Lamid, M., Sari, P. D. W., \& Suprapto, 
H. (2018). Teknik Pembesaran Udang Vaname (Litopenaeus Vannamei) Pada Tambak Pendampingan Pt Central Proteina Prima Tbk Di Desa Randutatah, Kecamatan Paiton, Probolinggo, Jawa Timur. Journal of Aquaculture and Fish Health, 7(2), 70.

Lin, Y. B., \& Tseng, H. C. (2019). FishTalk: An IoT-Based Mini Aquarium System. IEEE Access, 7, 35457-35469.

Madhavireddy, V., \& Koteswarrao, B. (2018). Smart Water Quality Monitoring System Using Iot Technology. International Journal of Engineering \& Technology, 7(4.36), 636.

Mulyono, S., Qomaruddin, M., \& Syaiful Anwar, M. (2018). Penggunaan Node-RED pada Sistem Monitoring dan Kontrol Green House berbasis Protokol MQTT. Jurnal Transistor Elektro Dan Informatika (TRANSISTOR EI, 3(1), 31-44.

Myre, E., \& Shaw, R. (2006). The Turbidity Tube : Simple and Accurate Measurement of Turbidity in the Field. Michigan Technological University, April, 1-15.

Rahmantya, K. F., Asianto, A. D., Wahyuni, T., Wibowo, D., \& Zunianto, A. K. (2018). Buku Pintar Kelautan dan Perikanan (Ismayanti, D. Arriyana, R. R. Damanti, \& R. Rahadian (eds.)). Pusat Data, Statistik, dan Informasi.

Rozie, F., Syarif, I., \& Rasyid, M. U. H. Al. (2020). Design and Implementation of Intelligent Aquaponics Monitoring System based on IoT. International Electronics Symposium (IES).

Saragih, N. S., Sukiyono, K., \& Cahyadinata, I. (2015). Risk Analysis of Production and Income the Shrimp Cultivation of the People in UrbanVillage Labuhan Deli, Sub District Medan Marelan, Medan City. Agrisep, 14,3952.

Supono. (2017). Teknologi Produksi Udang. Plantaxia.

Utojo, U., \& Tangko, A. M. (2008). Status, Masalah, dan Alternatif Pemecahan Masalah pada Pengembangan Budidaya Udang Vannamei (Litopenaeus vannamei) di Sulawesi Selatan. Media Akuakultur, 3(2), 118.

Wiguna, E. H., \& Subari, A. (2017). Rancang Bangun Sistem Monitoring Ketinggian Air Dan Kelembaban Tanah Pada Penyiram Tanaman Otomatis Dengan Hmi (Human Machine Interface) Berbasis Raspberry Pi Menggunakan Software Node-Red. Gema Teknologi, 19(3), 1. 